\title{
Community-Acquired Severe Sepsis: A Prospective Cohort Study
}

\author{
Cristiana Sousa1 ${ }^{*}$, Mariana Brandão², Orquídea Ribeiro3, Teresa Cardoso ${ }^{4}$ \\ ${ }^{1} \mathrm{MD}$, Internal Medicine Consultant, Service of Medicine, Centro Hospitalar de Trás-os-Montes e Alto Douro, \\ Chaves Unit, Chaves, Portugal \\ ${ }^{2} \mathrm{MD}$, Internal Medicine Consultant, Service of Medicine, Hospital de Santo António, Oporto Hospital Center, \\ University of Oporto, Porto, Portugal \\ ${ }^{3}$ Statistician at Department of Health Information and Decision Sciences, Center for Research in Health \\ Technologies and Information Systems (CINTESIS), Department of Biostatistics and Medical Informatics, \\ CINTESIS, Faculty of Medicine, University of Oporto, Porto, Portugal \\ ${ }^{4} \mathrm{MD}, \mathrm{PhD}$, Internal Medicine Consultant, Intensive Care Unit (UCIP), Hospital de Santo António, Oporto \\ Hospital Center, University of Oporto, Porto, Portugal \\ Email: ${ }^{*}$ cristiana.sevivas@gmail.com, mabrsi@gmail.com, orib@med.up.pt, cardoso.tmc@gmail.com
}

Received 15 July 2015; accepted 29 August 2015; published 1 September 2015

Copyright (C) 2015 by authors and Scientific Research Publishing Inc.

This work is licensed under the Creative Commons Attribution International License (CC BY). http://creativecommons.org/licenses/by/4.0/

(c) (7) Open Access

\section{Abstract}

Severe sepsis (SS) is one of the principal causes of admission in intensive care units (ICU), with an associated high morbidity and mortality. This study intends to characterize epidemiology of community-acquired SS (CASS) with special emphasis in the prevalence of multidrug resistant organisms and independent prognostic factors associated with ICU mortality. Methods: A prospective cohort study was conducted over 3.5 years, including all consecutive adult patients with CASS admitted to a mixed ICU, in a 600-bed university-affiliated hospital. Results: 1221 patients were admitted into the ICU, 25\% with CASS. The mean age was 59 years and the mean SAPS (simplified acute physiological score) was II 48. Most had septic shock (67\%). Respiratory (57\%), intra-abdominal $(22 \%)$ and urinary tract $(8 \%)$ infections were the main sources of infection. The overall isolation rate was $56 \%$. The most common identified microorganisms were Streptococcus pneumoniae (27\%), Escherichia coli (22\%), Staphylococcus aureus methicillin sensitive (8\%) and Haemophilus influenzae (7\%). The median ICU and hospital length of stay were 8 and 16 days, respectively. The ICU mortality rate was 33 . Independent risk factors associated with higher mortality were older age, higher SAPS II, septic shock and chronic hepatic disease. Female gender was independently associated with lower mortality. The type of microorganism was not significantly associated with prognosis. Conclusion: CASS was highly prevalent among ICU admissions. Independent risk factors associated with ICU mortality included older age and previous comorbidities, but mainly severity of acute illness reinforcing the need for early recognition and treatment. Multidrug resistant organisms were implicated in considerable proportion of community-acquired sepsis.

"Corresponding author. 
Keywords

\section{Community-Acquired Sepsis, Severe Sepsis, Septic Shock, ESKAPE Organisms, ICU Mortality}

\section{Introduction}

Severe sepsis is an infection associated with a systemic inflammatory response syndrome and acute organ dysfunction that may ultimately progress to fluid refractory cardiovascular dysfunction (septic shock) [1]. Early recognition and adequate treatment may prevent this unfavourable evolution and improve its prognosis.

It has a high and increasing incidence, with population aging and immunodeficiency states contributing to this [2]-[8]. Frequently it implies ICU admission, occurring in more than $10 \%$ of all ICU admissions [5] [6] [9]-[11]. Its economic impact is enormous [5], consuming nearly half of ICU bed-days [9]. It is a main subject of investigation, representing a significant healthcare burden worldwide [12]. This devastating syndrome can have a mortality rate as high as $65 \%$, and is assumed as the first cause of death in non-coronary ICU's [3] [9].

Although mortality has decrease slightly with the improvement of supportive clinical care and the early medical intervention [13], nowadays the purpose of sepsis investigation is directed primarily to the establishment of consensual guidelines to ameliorate patient care. That is the major goal of the Surviving Sepsis Campaign: raising the clinicians and public awareness to sepsis severity in order to allow early recognition of the syndrome along with the development and implementation of specific guidelines for the management of severe sepsis with the aim of obtaining a significant reduction in mortality [14]. The great emphasis of the campaign is on early identification and prompt antibiotics administration, if possibly preceded by cultures draw for microbiology, along with early goal-directed therapy, which are the main cornerstones to achieve the desirable goal.

Kumar et al. retrospectively studied the impact of delays in initiation of appropriate antimicrobial therapy in 2154 patients with sepsis and hypotension and found a strong correlation between delays in initiating antibiotic therapy and delays in-hospital mortality (adjusted odds ratio, 1119 deaths/1 hour delay). Each 1-h delay over the next $6 \mathrm{~h}$ decreased the average survival rates by $7.6 \%$. He also described that only $50 \%$ of patients received appropriate treatment during the first 6 hours [15], stressing the huge importance of early adequate antibiotic administration.

Along with the development of this campaign, a Portuguese network of ICUs was created in 2004, designated as the community-acquired sepsis admitted to ICU (SACiUCI) study group [16]. At the same time, our hospital was directly involved in the national coordination of the Surviving Sepsis Campaign and launched an educational campaign to help in the implementation of the recommendations. Our unit contributed with a large number of patients both to the SACiUCI study and to the SSC database [17].

The objectives of this study are to describe the prevalence of community-acquired severe sepsis among ICU admissions, the associated healthcare resource use and mortality rate, including independent prognostic factors. We also aim to characterize the microbiological profile involved in CASS with particular emphases in the prevalence of resistant microorganisms from the ESKAPE group (Enterococcus faecium Vancomycin-resistant, MRSA, ESBL producing E. coli and Klebsiella species, Klebsiella pneumonia Carbapenamase-hydrolyzing or MDR Acinectobacter baumannii, Pseudomonas aeruginosa or Enterobacter species) [18].

\section{Methods}

\subsection{Design}

Prospective cohort study, conducted over 3 and half years' time in a 12 bed mixed ICU, at a 600 -bed tertiary care university hospital. Hospital Research and Ethics Committee approved the study design and informed consent was waived due to its observational nature without any deviation from the current medical practice.

\subsection{Patients}

All adult patients (age $\geq 18$ years) consecutively admitted in the ICU between $1^{\text {st }}$ December 2004 and $31^{\text {th }}$ May 2008, were enrolled and screened for CASS. Patients were then followed-up until death or hospital discharge. 


\subsection{Definitions}

Infection was defined as a pathologic process caused by the invasion of normal sterile tissue or fluid or body cavity by a pathogenic or potentially pathogenic microorganism and/or clinically suspected infection plus the prescription of antimicrobial therapy [19].

Community-acquired infection was defined as the onset of infection before hospital admission or not present at admission that becomes evident in the first 48 hours [20].

Sepsis and sepsis-related conditions were defined according to the criteria proposed by the American College of Chest Physicians/Society of Critical Care Medicine (ACCP/SCCM) [1].

Patients were classified according to their primary diagnosis into five admission categories: medical noncoronary, coronary, elective surgery, non-elective surgery and trauma.

Patients with community-acquired sepsis were segregated in a cohort and divided according to mutually exclusive primary infection source: respiratory, urologic, intra-abdominal, skin and soft tissue and others.

For each patient, data collection comprised demographic characteristics (age, sex) and the presence of underlying disease/comorbidities. Metastatic cancer, haematological malignancy and acquired immunodeficiency syndrome (AIDS), were recorded using the Simplified Acute Physiology Score (SAPS II) definitions [21]; hepatic cirrhosis, chronic heart failure and chronic pulmonary failure were recorded using the Acute Physiology and Chronic Health Evaluation II definitions [22]; immunosuppression state was defined either by the administration in the 12 months prior to ICU admission of chemotherapy or radiation therapy or the administration of steroid treatment equivalent to $0.2 \mathrm{mg} / \mathrm{Kg} /$ day prednisolone for at least 3 months or $1 \mathrm{mg} / \mathrm{Kg} / \mathrm{day}$ for a week within the 3 months prior to ICU admission, haematological disease including chronic neutropenia ( $\geq 3$ months) or $\leq 1000 \mathrm{PN} / \mathrm{dL}$ and human immunodeficiency virus (HIV) status; chronic renal insufficiency, was defined as the need for chronic renal support or history of chronic renal failure with a serum creatinine level over $2 \mathrm{mg} / \mathrm{dl}$.

We grouped Enterococcus faecium vancomycin-resistant, methicillin-resistant Staphylococcus aureus (MRSA), extended-spectrum beta-lactamase (ESBL) producer E. coli and Klebsiella species, Klebsiella pneumonia Carbapenamase-hydrolyzing and MDR Acinectobacter baumannii, Pseudomonas aeruginosa and Enterobacter species in a group denominated ESKAPE [18].

The ICU and Hospital length of stay and the ICU and Hospital outcomes were also recorded and used as a measure of healthcare resources use.

\subsection{Data Collection}

Data were collected by physicians, who were responsible for reviewing all clinical information present on the medical records of each patient.

For each variable collected a precise definition was provided.

Each case report form included 228 items. Data collection included demographic data and comorbid diseases, the SAPS II [21] in the first ICU day, and microbiological and clinical data regarding the infectious episode.

\subsection{Data Management and Quality Control}

Data were collected prospectively using pre-printed case report forms with clear definitions and a specific database was created for this study, using SPSS software, version 16.

\subsection{Statistical Analyses}

Descriptive analysis was made of the background variables. Continuous variables were expressed as median and inter-quartile range (IQR) unless stated otherwise. Comparisons between groups were performed with two-tailed unpaired student's $T$ test, Pearson chi-square test, Mann-Whitney $U$ test or Kruskal-Wallis $H$ test for continuous variables according to data distribution. Fisher's exact test and chi-square test were used to carry out comparisons between categorical variables as appropriate.

The following variables were included in a univariate analysis with ICU mortality as the dependent variable: gender, age, SAPS II, type of ICU admission, severity of sepsis (severe sepsis or septic shock), the presence of comorbidities, immunossuppression, chronic hepatic disease, chronic renal dysfunction, chronic heart failure, chronic respiratory disease, hematologic disease, cancer, focus of infection, microbiological documentation of the responsible organism, positive blood cultures, type of microorganism, polymicrobial infections and infections by a microorganism of the ESKAPE group. Those with marginal association with mortality in the univa- 
riate analysis $(p$ value $<0.2)$ were screened for the multivariate analysis. The results of the multivariable models are expressed as odds ratio (OR) with $95 \%$ confidence interval $\left(\mathrm{CI}_{95 \%}\right)$ and $p$-values. Goodness of fit for all regressions was checked using Hosmer and Lemeshow test.

Statistical significance was defined as $p<0.05$. The statistical analysis was performed in $\operatorname{SPSS}^{\square} 16$ (SPSS Inc., Chicago IL).

\section{Results}

During the study period 1221 patients were admitted to the ICU, with a mean \pm SD age of $55 \pm 19$ years being 799 (65\%) male. Regarding type of admission: $486(40 \%)$ were medical non-coronary, 46 (4\%) coronary, 366 $(30 \%)$ trauma, $25(2 \%)$ elective surgery and $300(24 \%)$ non-elective surgery. The mean SAPS II was $45 \pm 16$. The median ICU length of stay (LOS) was 7 days (IQR 3-13) and hospital LOS 16 days (IQR: 7 - 32); 357 patients died in ICU (29\%) and 413 in hospital (34\%).

Of those, 300 patients $(25 \%)$ were admitted with community-acquired severe sepsis (CASS); the prevalence of CASS decreased slowly over the first 3 years, and increased again in the last semester (Figure 1).

Patients with CASS had a mean age of $59 \pm 17$ years and $59 \%$ were male. Only $30 \%$ of the patients had comorbidities, mainly: immunossuppression (8\%), chronic renal disease (8\%) and chronic respiratory disease (7\%) (Table 1). Distribution by source of infection was: respiratory (57\%), intra-abdominal (23\%), urinary (8\%), skin and soft tissue (4\%) and other (8\%); 67\% had septic shock. The median (IQR) ICU LOS was 8 (3 - 15) days and hospital LOS, 16 (7 - 27) days. The mean SAPS II was 48 corresponding to a predicted hospital mortality rate of $42 \%$, the actual hospital mortality was $37 \%(\mathrm{n}=111)$.

Comparing patients with septic shock with those with severe sepsis (Table 1), they were older (54 vs. 61 years, $p=0.002)$, had significantly more positive blood cultures $(13 \%$ vs. $46 \%, p=0.026)$, gram positive infection ( $52 \%$ vs. $45 \%, p=0.005)$, higher ICU LOS ( 9 vs. 6 days, $p=0.001)$ and ICU $(43 \%$ vs. $15 \%, p<0.001)$ and hospital $(46 \%$ vs. $20 \%, p<0.001)$ mortality rate. Regarding source of infection, respiratory infection was more frequently associated with severe sepsis $(65 \%$ vs. $53 \%, p=0.042)$ and urinary infection with septic shock $(3 \%$ vs. $11 \%, p=0.023)$ (Table 1$)$.

The seasonal characterization of CASS is showed in Table 2; respiratory infections were more prevalent in the winter and urinary infections in the summer and autumn $(p<0.005)$. No significant differences were observed in the type of microorganism or the presence of comorbidities.

The overall rate of microbiological documentation of infection was $56 \%$. The most common organisms identified were: Streptococcus pneumoniae $(30 \%, \mathrm{n}=44)$, Escherichia coli $(20 \%, \mathrm{n}=29)$, Methicillin-sensitive

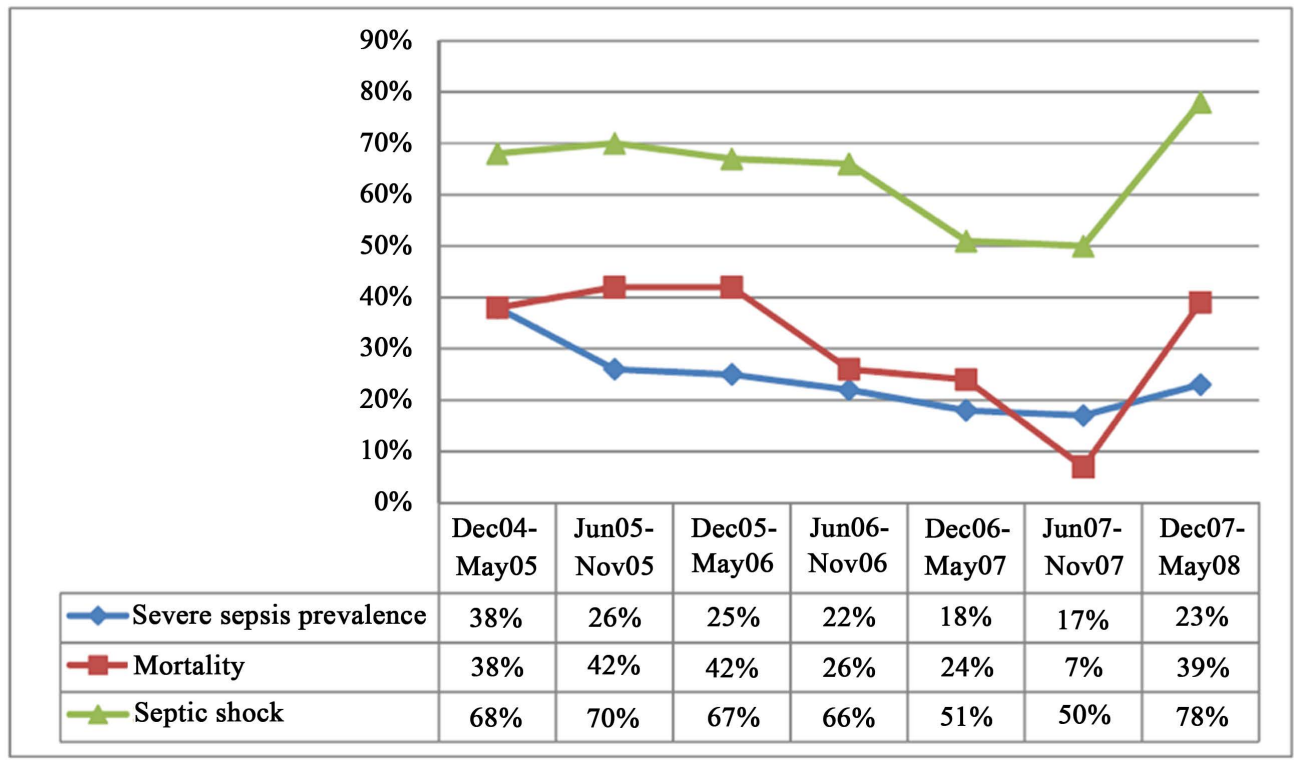

Figure 1. Evolution of severe sepsis and septic shock prevalence and hospital mortality rate, over the 3.5 years of the study period. 
Table 1. Characterization of patients with community-acquired sepsis and their stratification by severity of sepsis.

\begin{tabular}{|c|c|c|c|c|}
\hline & $\begin{array}{c}\text { Total } \\
(\mathbf{n}=\mathbf{3 0 0})\end{array}$ & $\begin{array}{l}\text { Severe sepsis } \\
\quad(\mathbf{n}=98)\end{array}$ & $\begin{array}{l}\text { Septic shock } \\
(\mathbf{n}=\mathbf{2 0 2})\end{array}$ & $p$ \\
\hline Male gender, n (\%) & $178(59)$ & $62(60)$ & $116(59)$ & $0.826^{*}$ \\
\hline Age, mean $\pm S D$ & $59 \pm 17$ & $54 \pm 18$ & $61 \pm 17$ & $0.002^{\mathfrak{E}}$ \\
\hline SAPS II, mean $\pm S D$ & $48 \pm 16$ & $40 \pm 13$ & $52 \pm 15$ & $<0.001^{\mathfrak{t}}$ \\
\hline Comorbidities, n (\%) & $89(30)$ & $26(25)$ & $63(32)$ & $0.225^{*}$ \\
\hline Immunossupression & $24(8)$ & $6(6)$ & $18(9)$ & $0.315^{*}$ \\
\hline Chronic hepatic disease & $10(4)$ & $3(3)$ & $10(5)$ & $0.553^{\&}$ \\
\hline Chronic renal disease & $23(8)$ & $5(5)$ & $18(9)$ & $0.186^{*}$ \\
\hline Chronic heart failure & $18(6)$ & $7(7)$ & $11(6)$ & $0.675^{*}$ \\
\hline Chronic respiratory disease & $22(7)$ & $10(10)$ & $12(6)$ & $0.254^{*}$ \\
\hline Haematologic disease & $5(2)$ & $0(0)$ & $5(3)$ & \\
\hline Cancer & $5(2)$ & $0(0)$ & $5(3)$ & \\
\hline \multicolumn{5}{|l|}{ Source of infection, $\mathrm{n}(\%)$} \\
\hline Respiratory & $171(57)$ & $67(65)$ & $104(53)$ & $0.042^{*}$ \\
\hline Intra-abdominal & $69(23)$ & $20(19)$ & $49(25)$ & $0.286^{*}$ \\
\hline Urinary & $24(8)$ & $3(3)$ & $21(11)$ & $\mathbf{0 . 0 2 3}^{\&}$ \\
\hline Skin and soft tissue & $12(4)$ & $58(18)$ & $94(22)$ & $0.225^{*}$ \\
\hline Other & $24(8)$ & $8(8)$ & $16(8)$ & $0.914^{*}$ \\
\hline Microbiological documented, n (\%) & $168(56)$ & $53(52)$ & $115(58)$ & $0.252^{*}$ \\
\hline Positive blood cultures, n (\%) & $59(20)$ & $13(13)$ & $46(23)$ & $0.026^{*}$ \\
\hline Type of microorganism, $\mathrm{n}(\%)$ & & & & $0.474^{\&}$ \\
\hline Gram positive & $71(42)$ & $23(46)$ & $48(41)$ & \\
\hline Gram negative & $62(37)$ & $15(30)$ & $47(40)$ & \\
\hline Other & $35(21)$ & $12(24)$ & $23(20)$ & \\
\hline ESKAPE & $19(11)$ & $5(10)$ & $14(12)$ & $1.000^{\&}$ \\
\hline Polimicrobian & $20(4)$ & $8(10)$ & $12(7)$ & $0.050^{*}$ \\
\hline ICU LOS, median (IQR) & $8(3-15)$ & $6(3-11)$ & $9(3-16)$ & $\mathbf{0 . 0 0 1}^{\#}$ \\
\hline Hospital LOS, median (IQR) & $16(7-27)$ & $15(8-24)$ & $16(5-28)$ & $0.451^{\#}$ \\
\hline Death in ICU, n (\%) & $100(33)$ & $15(15)$ & $85(43)$ & $<0.001^{*}$ \\
\hline Death in hospital, n (\%) & $111(37)$ & $21(20)$ & $90(46)$ & $<0.001^{*}$ \\
\hline
\end{tabular}

ICU—Intensive Care Unit; LOS—length of stay; IQR—inter-quartile range. ${ }^{*}$ Qui square test; ${ }^{\circledR}$ Mann-Whitney test; ${ }^{\circledR}$ Fisher exact test; ${ }^{*}$ Independent samples median test. 
Table 2. Seasonal distribution of patient's characteristics, focus and severity of infection, type of micro-organisms and outcome.

\begin{tabular}{|c|c|c|c|c|c|c|}
\hline & $\begin{array}{c}\text { TOTAL } \\
(n=897)\end{array}$ & $\begin{array}{c}\text { Spring } \\
(\mathrm{n}=\mathbf{2 0 2})\end{array}$ & $\begin{array}{l}\text { Summer } \\
(\mathrm{n}=\mathbf{2 0 1})\end{array}$ & $\begin{array}{c}\text { Autumn } \\
(\mathrm{n}=212)\end{array}$ & $\begin{array}{c}\text { Winter } \\
(\mathrm{n}=\mathbf{2 8 2})\end{array}$ & $p^{*}$ \\
\hline Male gender, n (\%) & $178(59)$ & $48(63)$ & $21(41)$ & $44(70)$ & $65 n(59)$ & $0.016^{*}$ \\
\hline Age, median (IQR) & $59 \pm 17$ & $59 \pm 16$ & $60 \pm 17$ & $55 \pm 18$ & $60 \pm 18$ & $0.297^{\S}$ \\
\hline SAPS II, median $(I Q R)$ & $48 \pm 16$ & $51 \pm 15$ & $47 \pm 17$ & $44 \pm 15$ & $48 \pm 16$ & $0.076^{\S}$ \\
\hline Septic shock, n (\%) & $197(66)$ & $57(75)$ & $30(59)$ & $43(68)$ & $67(61)$ & $0.152^{*}$ \\
\hline Comorbidities, $n(\%)$ & $89(30)$ & $26(34)$ & $10(20)$ & $21(33)$ & $32(29)$ & $0.305^{*}$ \\
\hline \multicolumn{7}{|l|}{ Focus of infection, n (\%) } \\
\hline Respiratory & $171(57)$ & $38(50)$ & $21(41)$ & $32(51)$ & $80(73)$ & $<0.001^{*}$ \\
\hline Intra-abdominal & $69(23)$ & $19(25)$ & $17(33)$ & $13(21)$ & $20(18)$ & $0.184^{*}$ \\
\hline Urinary & $24(8)$ & $6(8)$ & $8(16)$ & $8(13)$ & $2(2)$ & $0.004^{k}$ \\
\hline Skin and soft tissue & $12(4)$ & $2(3)$ & $2(4)$ & $4(6)$ & $4(4)$ & $0.730^{\&}$ \\
\hline Other & $24(8)$ & $11(15)$ & $3(6)$ & $6(10)$ & $4(4)$ & $0.054^{\&}$ \\
\hline Microbiological documented, n (\%) & $168(56)$ & $46(61)$ & $24(47)$ & $38(60)$ & $60(55)$ & $0.419^{*}$ \\
\hline Positive blood cultures, n (\%) & $59(20)$ & $17(22)$ & $10(20)$ & $13(21)$ & $19(17)$ & $0.855^{*}$ \\
\hline Type of microorganism, n (\%) & & & & & & $0.172^{\&}$ \\
\hline Gram positive & $71(42)$ & $15(33)$ & $9(438)$ & $16(42)$ & $31(52)$ & \\
\hline Gram negative & $62(37)$ & $17(37)$ & $13(54)$ & $13(34)$ & $19(32)$ & \\
\hline Others & $35(21)$ & $14(30)$ & $2(8)$ & $9(24)$ & $10(17)$ & \\
\hline ESKAPE & $19(11)$ & $5(11)$ & $4(17)$ & $2(5)$ & $8(13)$ & $0.477^{\&}$ \\
\hline Polimcrobian, n (\%) & $20(7)$ & $7(9)$ & $2(4)$ & $5(8)$ & $6(6)$ & $0.630^{\&}$ \\
\hline Death in ICU, n (\%) & $100(33)$ & $27(36)$ & $15(29)$ & $17(27)$ & $41(37)$ & $0.491^{*}$ \\
\hline Death in hospital, n (\%) & $111(37)$ & $31(41)$ & $15(29)$ & $18(29)$ & $47(43)$ & $0.159^{*}$ \\
\hline
\end{tabular}

IQR-Inter-quartile range. ${ }^{*}$ Qui square test; ${ }^{\S}$ one-way ANOVA test; ${ }^{\&}$ Fisher exact test.

Staphylococcus aureus $(8 \%, \mathrm{n}=12)$, Haemophilus influenzae $(7 \%, \mathrm{n}=10)$, Mycobacterium tuberculosis $(6 \%, \mathrm{n}$ $=4)$, MRSA $(5 \%, \mathrm{n}=3)$ and Pseudomonas aeruginosa $(5 \%, \mathrm{n}=3)$. Polymicrobial infections accounted for $12 \%$ $(\mathrm{n}=20)$ of infections with microbiological documentation. Microorganisms from the ESKAPE group were responsible for $11 \%(n=19)$ of all CASS.

\subsection{Focus of Infection}

In respiratory infections, the most common microorganisms involved were Streptococcus pneumonia and Haemophilus influenza; of notice is the third place taken by the ESKAPE group (9\%) and Mycobacterium tuberculosis as the third single agent in $7 \%$ of all respiratory infections with isolation.

In intra-abdominal infections $E$. coli was the main agent $(41 \%)$, with polimicrobian infections accounting for $28 \%$ of the isolations; pathogens from the ESKAPE group were present in $9 \%$ of all isolations.

Urinary infections had the highest isolation rate $(79 \%)$ with E. coli predominating (68\%), and resistant pathogens (ESKAPE) present in $8 \%$ of all infections with microbiological documentation.

In skin and soft tissue Methicillin sensitive staphylococcus aureus (MSSA) (50\%) and polimicrobian (33\%) infections were the rule; ESKAPE pathogens were present in 25\% (Table 3).

Blood cultures were collected in all patients but they were positive only in $20 \%(n=59): 14 \%$ in respiratory 
Table 3. Microbiological profile by the main focus of infection.

\begin{tabular}{|c|c|c|c|}
\hline & Isolation rate, $\%$ (n) & Microbe species, \% (n) & Microbe group, \% (n) \\
\hline Respiratory $(\mathrm{n}=171)$ & $54 \%(\mathrm{n}=92)$ & $\begin{array}{l}\text { Streptococcus pneumoniae-48\% }(\mathrm{n}=44) \\
\text { Haemophilus influenza-11\% }(\mathrm{n}=10) \\
\text { Mycobacterium tuberculosis-7\% }(\mathrm{n}=6) \\
\text { Staphylococcus aureus } M S-5 \%(\mathrm{n}=5)\end{array}$ & $\begin{array}{c}\text { Gram positive-53\% }(\mathrm{n}=49) \\
\text { Gram negative-27\% }(\mathrm{n}=25) \\
\text { Fungi-5\% }(\mathrm{n}=5) \\
\text { Others-8\% }(\mathrm{n}=7) \\
\text { Polimicrobian-7\% }(\mathrm{n}=6) \\
\text { ESKAPE-9\% }(\mathrm{n}=8)\end{array}$ \\
\hline Intra-abdominal $(\mathrm{n}=69)$ & $46 \%(n=32)$ & $\begin{array}{c}\text { Escherichia coli- } 41 \%(\mathrm{n}=13) \\
\text { Enterococcus faecium-6\%(n=2) } \\
\text { Streptococcus agalactiae-6\% }(\mathrm{n}=2)\end{array}$ & $\begin{array}{c}\text { Gram positive-22\% }(\mathrm{n}=7) \\
\text { Gram negative-50\% }(\mathrm{n}=16) \\
\text { Polimcrobian-28\% }(\mathrm{n}=9) \\
\text { ESKAPE-9\% }(\mathrm{n}=3)\end{array}$ \\
\hline Urinary $(n=24)$ & $79 \%(n=19)$ & Escherichia coli-68\% $(\mathrm{n}=13)$ & $\begin{array}{c}\text { Gram positive-16\% }(\mathrm{n}=3) \\
\text { Gram negative-74\% }(\mathrm{n}=14) \\
\text { Polimicrobian-10\% }(\mathrm{n}=2) \\
\text { ESKAPE- } 8 \%(\mathrm{n}=2)\end{array}$ \\
\hline Skin $(\mathrm{n}=12)$ & $50 \%(n=6)$ & Staphylococcus aureus $M S-50 \%(\mathrm{n}=2)$ & $\begin{array}{l}\text { Gram positive- } 17 \%(\mathrm{n}=1) \\
\text { Gram negative- } 50 \%(\mathrm{n}=3) \\
\text { Polimicrobian-33\%(n=2) } \\
\text { ESKAPE-25\% }(\mathrm{n}=3)\end{array}$ \\
\hline
\end{tabular}

MS—Methicillin-sensitive; MR—Methicillin resistant.

infections $(\mathrm{n}=23), 16 \%$ in intra-abdominal $(\mathrm{n}=11), 33 \%$ in urinary $(\mathrm{n}=8)$ and $25 \%$ in skin and soft tissue $(\mathrm{n}=$ $3)$.

\subsection{Prognosis Factors in CASS}

In the univariate logistic regression analysis age, sex, SAPS II, type of admission, previous comorbidities, namely chronic hepatic disease, hematologic disease and cancer were associated with ICU mortality (Table 4). The final multivariable model retained: age (adjusted $\mathrm{OR}=1.022$ per year, $\mathrm{CI}_{95 \%}, 1.004-1.040$ ), SAPSII (adjusted $\mathrm{OR}=1.039$ per point, $\mathrm{CI}_{95 \%}, 1.018-1.060$ ), chronic hepatic disease (adjusted $\mathrm{OR}=4.481, \mathrm{CI}_{95 \%}, 1.159$ 17.325 ) and septic shock (adjusted $\mathrm{OR}=2.511, \mathrm{CI}_{95 \%}, 1.293-4.876$ ), independently associated with increased ICU mortality. Female gender (adjusted $\mathrm{OR}=0.550, \mathrm{CI}_{95 \%}, 0.312-0.971$ ) appeared to have a protective effect.

\section{Discussion}

\subsection{Main Findings}

We found a high prevalence of community-acquired severe sepsis among ICU admissions (25\%), within the range reported by similar studies: the SOAP study [23] (30\%), the study from Alberti et al. [24] (14\%), the Episepsis study (15\%) [3] and the study by Padkin et al. [25] (27\%).

Our unit admits mainly patients from the emergency room, non-elective surgery, and through the medical emergency system, patients with higher likelihood of having infection as cause of admission, justifying the high prevalence of severe sepsis. On the other hand, this prevalence is lower than the aforementioned studies [23] [24] probably because we only included patients with community-acquired sepsis which probably underestimate the true prevalence of severe sepsis.

Previous studies have documented a steady increase in the rate of sepsis; the Episepsis study group describe a $75 \%$ increase among ICU admissions over a decade [3]; Martin and colleagues also described an annual increase among the United States hospitals of 8.7\% [26] and Harrison et al. [13] a 5\% increase over 5 years among United Kingdom critical care admissions. The improved care of elderly and immunocompromised patients, plus the widespread use of invasive devices, was advanced as the contributing factors for this increasing rate [27] [28].

Contrarily, we found a steady decrease in the sepsis rate and associated mortality among ICU admissions over the first 3 years, and then a sudden increase in the last semester. Our study began at the same time as the implementation of the Surviving Sepsis Campaign in Portugal being the national coordinator from our unit, which 
Table 4. Univariate logistic regression model with ICU mortality as dependent variable.

\begin{tabular}{|c|c|c|c|c|c|c|c|}
\hline & \multicolumn{3}{|c|}{ Status } & \multirow[b]{3}{*}{$p$} & \multirow[b]{3}{*}{$\mathrm{OR}$} & \multirow[b]{3}{*}{ IC $95 \%$} & \\
\hline & $\begin{array}{c}\text { Total } \\
(n=300)\end{array}$ & $\begin{array}{c}\text { Alive } \\
(n=200 ; 68 \%)\end{array}$ & $\begin{array}{c}\text { Death } \\
(n=100 ; 33 \%)\end{array}$ & & & & \\
\hline & $\mathrm{n}(\%)$ & $\mathrm{n}(\%)$ & $\mathrm{n}(\%)$ & & & & \\
\hline Age, mean (sd) & $59(17)$ & $56(17)$ & $63(16)$ & $0.001^{\ddagger}$ & 1.026 & 1.011 & 1.042 \\
\hline Gender female & $122(41)$ & $89(45)$ & $33(33)$ & $0.056^{*}$ & 0.614 & 0.372 & 1.014 \\
\hline Surgical patients & $91(30)$ & $67(34)$ & $24(24)$ & $0.092^{*}$ & 0.627 & 0.364 & 1.081 \\
\hline SAPS II, mean (sd) & $48(16)$ & $44(15)$ & $55(15)$ & $<0.001^{\ddagger}$ & 1.051 & 1.032 & 1.070 \\
\hline Comorbidities & $89(30)$ & $52(26)$ & $37(37)$ & $0.049^{*}$ & 1.672 & 0.999 & 2.796 \\
\hline Imunossupression & $24(8)$ & $13(7)$ & $11(11)$ & $0.176^{*}$ & 1.778 & 0.766 & 4.125 \\
\hline Chronic hepatic disease & $13(4)$ & $5(3)$ & $8(8)$ & $0.0366^{* *}$ & 3.391 & 1.080 & 10.652 \\
\hline Chronic renal disease & $23(8)$ & $17(9)$ & $6(6)$ & $0.443^{*}$ & 0.687 & 0.262 & 1.801 \\
\hline Chronic heart failure & $18(6)$ & $12(6)$ & $6(6)$ & $1.000^{*}$ & 1.000 & 0.364 & 2.748 \\
\hline Chronic respiratory & $22(7)$ & $14(7)$ & $8(8)$ & $0.754^{*}$ & 1.155 & 0.468 & 2.853 \\
\hline Heaemathologic disease & $5(2)$ & $1(1)$ & $4(4)$ & $0.044^{*}$ & 8.292 & 0.914 & 75.192 \\
\hline Cancer & $5(2)$ & $1(1)$ & $4(4)$ & $0.044^{*}$ & 8.292 & 0.914 & 75.192 \\
\hline \multicolumn{8}{|l|}{ Station } \\
\hline Spring & $76(25)$ & $49(25)$ & $27(27)$ & $0.488^{*}$ & 1.000 & - & \\
\hline Summer & $51(17)$ & $36(18)$ & $15(15)$ & & 0.756 & 0.352 & 1.623 \\
\hline Autumn & $63(21)$ & $46(23)$ & $17(17)$ & & 0.671 & 0.324 & 1.389 \\
\hline Winter & $110(37)$ & $69(35)$ & $41(41)$ & & 1.078 & 0.587 & 1.981 \\
\hline Pneumonia & $171(57)$ & $115(58)$ & $56(56)$ & $0.805^{*}$ & 0.941 & 0.580 & 1.527 \\
\hline Abdominal & $69(23)$ & $46(23)$ & $23(23)$ & $1.000^{*}$ & 1.000 & 0.565 & 1.769 \\
\hline UTI & $24(8)$ & $18(9)$ & $6(6)$ & $0.367^{*}$ & 0.645 & 0.248 & 1.680 \\
\hline Other focus & $24(8)$ & $12(6)$ & $12(12)$ & $0.071^{*}$ & 2.136 & 0.923 & 4.945 \\
\hline Septic shock & $202(67)$ & $117(59)$ & $85(85)$ & $<0.001^{*}$ & 4.020 & 2.169 & 7.449 \\
\hline Microbiological documented & $168(56)$ & $114(57)$ & $54(54)$ & $0.622^{*}$ & 0.886 & 0.546 & 1.435 \\
\hline Positive blood cultures & $59(20)$ & $33(17)$ & $26(26)$ & $0.051^{*}$ & 1.778 & 0.993 & 3.183 \\
\hline Polimicrobian & $20(7)$ & $14(7)$ & $6(6)$ & $0.743^{*}$ & 0.848 & 0.316 & 2.278 \\
\hline \multicolumn{8}{|l|}{ Type of microorganism } \\
\hline Gram negative & $62(37)$ & $45(39)$ & $17(32)$ & $0.602^{*}$ & 1.000 & - & \\
\hline Gram positive & $71(42)$ & $46(40)$ & $25(46)$ & & 1.439 & 0.686 & 3.017 \\
\hline Other & $35(21)$ & $23(20$ & $12(22)$ & & 1.381 & 0.565 & 3.375 \\
\hline ESKAPE & $19(11)$ & $10(9)$ & $9(17)$ & $0.290^{*}$ & 1.001 & 0.996 & 1.006 \\
\hline
\end{tabular}

Sd—standard deviation. ${ }^{*}$ Chi-square independency test ${ }^{* *}$ Fisher exact test; ${ }^{*}$ t-Student test. 
probably contributed to a higher motivation at the institution, particularly at the Emergency Department, high dependency units and ICU, probably to an early recognition and treatment of sepsis, preventing patient deterioration and need for intensive care treatment. After the quick off enthusiasm we assisted to a sudden increase of the CASS prevalence among ICU admissions, to the levels recorded at the beginning of the study. Ferrer et al. [29] also describe that following a national educational campaign there was an increase in the compliance with Surviving Sepsis Campaign recommendations but the lack of a continuous effort resulted in a long time return to the baseline.

The mortality rate found for severe sepsis was 33\% in ICU and 37\% in hospital, in the middle range of descriptions from similar studies; mortality rate among severe sepsis patients goes from $16 \%$ to $48 \%$ at ICU [11] [25] [30] [31], 28\% to $54 \%$ in hospital [2] [11] [25] [31]-[34] and $35 \%$ to $60 \%$ at 28 -days mortality [4] [6] [10]. Reports come from all over the world and what is common is the huge impact of severe sepsis in mortality. These wide variations in mortality rate are explained by different case-mix, particularly different severity of patients included and also different outcome end-points. In our study the hospital mortality found (37\%) was lower than predicted by SAPS II (42\%).

We identified age, SAPS II, septic shock and chronic hepatic disease as independent factors associated with ICU mortality. Frequently clinical trials exclude patients believed to be at higher risk of death (as elderly, patients with HIV disease and malignancy); Angus found that these patients are a large proportion of the sepsis population and confirmed that these patients in fact died more [2]. We included these group of patients but immunosuppression and malignancy were not independently associated with ICU mortality.

Female sex was found to be independently associated with lower ICU mortality. Several studies also describe sex as an important prognostic factor in patients with sepsis, but with contradictory results [35] [36], and without a physiopathological explanation for it. Additional other large studies did not found a statistically significant association of sex and sepsis outcome or severity [3] [37]. The role of gender as a prognostic factor is clearly an open topic.

There has been a suggestion of a seasonal variation in the incidence and mortality of sepsis and severe sepsis, consistently higher during winter and predominantly related to respiratory sepsis [38]. In our study we also observed a seasonal variation of the source of infection, but not in severity or mortality.

The median ICU and hospital LOS found were similar to the description by Brun-Buisson et al. [39] and Finfer et al. [6], reinforcing severe sepsis as a medical problem with high healthcare resource utilization.

Our isolation rate (56\%) was similar to the study from Alberti and colleagues (55\%) [5] and lower than the Episepsis group (62\%) [3]. Considering that we have just included community-acquired sepsis is probably underestimated, since community-acquired infections generally have a much lower isolation rate than hospital or ICU-acquired infection, where it can be higher than 70\%. Alberti and Brun-Buisson [40], in review found that the proportion of cases with microbiological documentation of an infection is relatively low in epidemiological studies, with the lowest rates reported lower than 50\% [41] [42]. In a small number of studies, higher rates of documentation were associated with ICU-acquired infection (85\% in the Vincent [43] et al. study and $86 \%$ in a study by Alberti et al. [44]), which may reflect the fact that microbiological samples are more likely to be obtained and be positive in the ICU.

The microbiological findings also vary according to the type of patients included: community, hospital or ICU-acquired infection; focus of infection; immunodepressed patients; among others. Alberti and colleagues in an international study that included all focus of infection, community, hospital and ICU-acquired found a predominance of gram-negative bacilli, followed by gram positive cocci [5]. The Episepsis group, a multicentre French inception study recorded gram positive as the organisms responsible for the majority of the infections [3]. We also found a gram positive predominance. Off notice in our study is the third place occupied by Mycobacterium tuberculosis in respiratory sepsis, reminding that this is still an important aetiology in our country [45].

We also found that $11 \%$ of all community-acquired severe sepsis admitted to our ICU was caused by organisms belonging to the ESKAPE group; this group of MDR organisms has been considered by the Infectious Diseases Society of America a motive of increase concern among community and hospital-acquired infections [18]. Recording the prevalence of these microorganisms according to place of acquisition of infection, is fundamental for adjusting empiric antibiotic recommendations.

\subsection{Strengths}

The main strengths of our study is the long study period that allowed not only to observe trends in prevalence 
and mortality rates but also to research for seasonal variations.

The use of standardized and international definitions as well as universally approved severity scores, allowed comparison with studies from different countries.

The detailed microbiological characterization allowed the recording of MDR, namely from the ESKAPE group among community-acquired severe sepsis by focus of infection, helping in the planning of first intention antibiotic therapy.

Finally, its prospective methodology using trained and dedicated data collectors along with detailed data checking performed at the time of data entry allowed the building of a high-quality database. No patient was lost to follow up.

\subsection{Limitations}

The major limitation is being a single center study which could limit the external applicability of the findings, nevertheless general data like sepsis prevalence and mortality were comparable with studies from all around the world suggesting that additional findings could be generalized.

We only addressed community-acquired severe sepsis, so data cannot be extrapolated to nosocomial sepsis including ICU-acquired sepsis, nor patients without acute organ dysfunction.

The regression model was adjusted for potential confounders identified but there is always the possibility of unforeseen factors for which we have not adjusted and that could have altered the results.

\section{Conclusions}

Community-acquired severe sepsis admitted into ICU care remains an important healthcare problem with an associated high mortality and healthcare resource consumption.

ICU mortality was independently associated with increasing age, chronic liver disease and severity of acute disease (septic shock and higher SAPS II). Female sex was independently associated with lower ICU mortality.

MDR organisms, namely those belonging to the ESKAPE group, are responsible for an important proportion of community-acquired sepsis, reinforcing the need for continuous surveillance to update empiric antibiotic therapy recommendations.

\section{Authors' Contributions}

Teresa Cardoso has coordinated data acquisition and its interpretation.

Orquídea Ribeiro and Teresa Cardoso made the statistical analysis.

All authors have made substantial contribution in the drafting, revising and final approval of the version to be published.

\section{Acknowledgements}

This paper is supported by an unrestricted grant from ASSUCIP-Associação dos Amigos da Unidade de Cuidados Intensivos Polivalente, Hospital de Santo António, Porto, Portugal (Intensive Care Unit Support Association).

\section{Competing Interests}

The authors declare that they have no competing interests.

\section{References}

[1] Bone, R.C., Balk, R.A., Cerra, F.B., et al. (1992) Definitions for Sepsis and Organ Failure and Guidelines for the Use of Innovative Therapies in Sepsis: ACCP/SCCM Consensus Conference Committee. American College of Chest Physicians/Society of Critical Care Medicine. Chest, 101, 1644-1655. http://dx.doi.org/10.1378/chest.101.6.1644

[2] Angus, D.C., Linde-Zwirble, W.T., Lidicker, J., Clermont, G., Carcillo, J. and Pinsky, M.R. (2001) Epidemiology of Severe Sepsis in the United States: Analysis of Incidence, Outcome, and Associated Costs of Care. Critical Care Medicine, 29, 1303-1310. http://dx.doi.org/10.1097/00003246-200107000-00002

[3] Brun-Buisson, C., Meshaka, P., Pinton, P. and Vallet, B. (2004) EPISEPSIS: A Reappraisal of the Epidemiology and 
Outcome of Severe Sepsis in French Intensive Care Units. Intensive Care Medicine, 30, 580-588. http://dx.doi.org/10.1007/s00134-003-2121-4

[4] Brun-Buisson, C. (2000) The Epidemiology of the Systemic Inflammatory Response. Intensive Care Medicine, 26, S64-S74. http://dx.doi.org/10.1007/s001340051121

[5] Alberti, C., Brun-Buisson, C., Burchardi, H., Martin, C., Goodman, S., Artigas, A., Sicignano, A., Palazzo, M., Moreno, R., Boulmé, R., Lepage, E. and Le Gall, J.R. (2002) Epidemiology of Sepsis and Infection in ICU Patients from an International Multicentre Cohort Study. Intensive Care Medicine, 28, 108-121. http://dx.doi.org/10.1007/s00134-001-1143-Z

[6] Finfer, S., Bellomo, R., Lipman, J., French, C., Dobb, G. and Myburgh, J. (2004) Adult-Population Incidence of Severe Sepsis in Australian and New Zealand Intensive Care Units. Intensive Care Medicine, 30, 589-596. http://dx.doi.org/10.1007/s00134-004-2157-0

[7] Vincent, J.L., Sakr, Y., Sprung, C.L., Ranieri, V.M., Reinhart, K., Gerlach, H., Moreno, R., Carlet, J., Le Gall, J.R. and Payen, D. (2006) Sepsis in European Intensive Care Units: Results of the SOAP Study. Critical Care Medicine, 34, 344-353. http://dx.doi.org/10.1097/01.CCM.0000194725.48928.3A

[8] Angus, D.C. and Wax, R.S. (2001) Epidemiology of Sepsis: An Update. Critical Care Medicine, 29, S109-S115. http://dx.doi.org/10.1097/00003246-200107001-00035

[9] Moss, M. and Martin, G.S. (2004) A Global Perspective on the Epidemiology of Sepsis. Intensive Care Medicine, 30, 527-529. http://dx.doi.org/10.1007/s00134-004-2182-z

[10] Silva, E., Pedro Mde, A., Sogayar, A.C., Mohovic, T., Silva, C.L., Janiszewski, M., Cal, R.G., de Sousa, E.F., Abe, T.P., de Andrade, J., de Matos, J.D., Rezende, E., Assunção, M., Avezum, A., Rocha, P.C., de Matos, G.F., Bento, A.M., Corrêa, A.D., Vieira, P.C. and Knobel, E. (2004) Brazilian Sepsis Epidemiological Study (BASES Study). Critical Care Medicine, 8, R251-R260. http://dx.doi.org/10.1186/cc2892

[11] Karlsson, S., Varpula, M., Ruokonen, E., Pettila, V., Parviainen, I., Ala-Kokko, T.I., Kolho, E. and Rintala, E.M. (2007) Incidence, Treatment, and Outcome of Severe Sepsis in ICU-Treated Adults in Finland: The Finnsepsis Study. Intensive Care Medicine, 33, 435-443. http://dx.doi.org/10.1007/s00134-006-0504-z

[12] Hodgin, K.E. and Moss, M. (2008) The Epidemiology of Sepsis. Current Pharmaceutical Design, 14, $1833-1839$. http://dx.doi.org/10.2174/138161208784980590

[13] Harrison, D.A., Welch, C.A. and Eddleston, J.M. (2006) The Epidemiology of Severe Sepsis in England, Wales and Nothern Ireland, 1996 to 2004: Secondary Analysis of High Quality Clinical Database, the ICNARC Case Mix Programme Database. Critical Care, 10, R42. http://dx.doi.org/10.1186/cc4854

[14] Dellinger, R.P., Levy, M.M., Carlet, J.M., Bion, J., Parker, M.M., Jaeschke, R., et al. (2008) Surviving Sepsis Campaign: International Guidelines for Management of Severe Sepsis and Septic Shock: 2008. Critical Care Medicine, 36, 296-327. http://dx.doi.org/10.1097/01.CCM.0000298158.12101.41

[15] Kumar, A., Roberts, D., Wood, K., Light, B., Parrillo, J.E., Sharma, S., et al. (2006) Duration of Hypotension before Initiation of Effective Antimicrobial Therapy Is the Critical Determinant of Survival in Human Septic Shock. Critical Care Medicine, 34, 1589-1596. http://dx.doi.org/10.1097/01.CCM.0000217961.75225.E9

[16] Cardoso, T., Carneiro, A.H., Ribeiro, O., Teixeira-Pinto, A. and Costa-Pereira, A. (2010) Reducing Mortality in Severe Sepsis with the Implementation of a Core 6-Hour Bundle: Results from the Portuguese Community-Acquired Sepsis Study (SACiUCI Study). Critical Care, 14, R83. http://dx.doi.org/10.1186/cc9008

[17] Levy, M.M., Dellinger, R.P., Townsend, S.R., Linde-Zwirble, W.T., Marshall, J.C., Bion, J., Schorr, C., Artigas, A., Ramsay, G., Beale, R., Parker, M.M., Gerlach, H., Reinhart, K., Silva, E., Harvey, M., Regan, S. and Angus, D.C. (2010) The Surviving Sepsis Campaign: Results of an International Guideline-Based Performance Improvement Program Targeting Severe Sepsis. Intensive Care Medicine, 36, 222-231. http://dx.doi.org/10.1007/s00134-009-1738-3

[18] Boucher, H.W., Talbot, G.H., Bradley, J.S., Edwards, J.E., Gilbert, D., Rice, L.B., et al. (2009) Bad Bugs, No Drugs: No ESKAPE! An Update from the Infectious Diseases Society of America. Clinical Infectious Diseases, 48, 1-12. http://dx.doi.org/10.1086/595011

[19] Levy, M.M., Fink, M.P., Marshall, J.C., Abraham, E., Angus, D., Cook, D., Cohen, J., Opal, S.M., Vincent, J.L. and Ramsay, G. (2003) 2001 SCCM/ESICM/ACCP/ATS/SIS International Sepsis Definitions Conference. Critical Care Medicine, 31, 1250-1256. http://dx.doi.org/10.1097/01.CCM.0000050454.01978.3B

[20] Garner, J.S., Jarvis, W.R., Emori, T.G., Horan, T.C. and Hughes, J.M. (1996) CDC Definitions for Nosocomial Infections. In: Olmsted, R.N., Ed., APIC Infection Control and Applied Epidemiology: Principles and Practice, Mosby, St. Louis, A1-A20.

[21] Le Gall, J.R., Lemeshow, S. and Saulnier, F. (1993) A New Simplified Acute Physiology Score (SAPS II) Based on a European/North American Multicenter Study. JAMA, 270, 2957-2963. http://dx.doi.org/10.1001/jama.1993.03510240069035 
[22] Knaus, W.A., Draper, E.A., Wagner, D.P. and Zimmerman, J.E. (1985) APACHE II: A Severity of Disease Classification System. Critical Care Medicine, 13, 818-829. http://dx.doi.org/10.1097/00003246-198510000-00009

[23] Vincent, J.L., Sakr, Y., Sprung, C.L., Marco Ranieri, V., Reinhart, K., Gerlach, H., et al. (2006) Sepsis in European Intensive Care Units: Results of the SOAP Study. Critical Care Medicine, 34, 344-353. http://dx.doi.org/10.1097/01.CCM.0000194725.48928.3A

[24] Alberti, C., Brun-Buisson, C., Goodman, S.V., Guidici, D., Granton, J., Moreno, R., et al., the European Sepsis Group (2003) Influence of Systemic Inflammatory Response Syndrome and Sepsis on Outcome of Critically Ill Infected Patients. American Journal of Respiratory and Critical Care Medicine, 168, 77-84. http://dx.doi.org/10.1164/rccm.200208-785OC

[25] Padkin, A., Goldfrad, C., Brady, A.R., Young, D., Black, N. and Rowan, K. (2003) Epidemiology of Severe Sepsis Occurring in the First 24 Hrs in Intensive Care Units in Engand, Wales, and Nothern Ireland. Critical Care Medicine, 31, 2332-2338. http://dx.doi.org/10.1097/01.CCM.0000085141.75513.2B

[26] Martin, G.S., Mannino, D.M., Eaton, S. and Moss, M. (2003) The Epidemilogy of Sepsis in the United Sates from 1979 through 2000. New England Journal of Medicine, 348, 1546-1554. http://dx.doi.org/10.1056/NEJMoa022139

[27] Angus, D.C. and Wax, R.S. (2001) Epidemiology of Sepsis: An Update. Critical Care Medicine, 29, S109-S116. http://dx.doi.org/10.1097/00003246-200107001-00035

[28] Safdar, N. and Maki, D.G. (2002) The Commonality of Risk Factors for Nosocomial Colonization and Infection with Anti-Microbial-Resistant Staphylococcus Aureus, Enterococcus, Gram-Negative Bacilli, Clostridium Difficile and Candida. Annals of Internal Medicine, 136, 834-844. http://dx.doi.org/10.7326/0003-4819-136-11-200206040-00013

[29] Ferrer, R., Artigas, A., Levy, M.M., Blanco, J., González-Díaz, G., Garnacho-Montero, J., et al., the EduSepsis Study Group (2008) Improvement in Process of Care and Outcome after a Multicenter Severe Sepsis Educational Program in Spain. JAMA, 299, 2294-2303. http://dx.doi.org/10.1001/jama.299.19.2294

[30] Engel, C., Brunkhorst, F., Bone, H.G., Brunkhorst, R., Gerlach, H., Grond, S., et al. (2007) Epidemiology of Sepsis in Germany: Results from a National Prospective Mulitcenter Study. Intensive Care Medicine, 33, 606-618. http://dx.doi.org/10.1007/s00134-006-0517-7

[31] Beale, R., Reinhart, K., Brunkhorst, F.M., Dobb, G., Levy, M., Martin, G., et al. (2009) Promoting Global Research Excellence in Severe Sepsis (PROGRESS): Lessons from an International Sepsis Registry. Infection, 37, $222-232$. http://dx.doi.org/10.1007/s15010-008-8203-Z

[32] Martin, C.M., Priestap, F., Fisher, H., Fowler, R.A., Heyland, D.K., Keenan, S., et al. (2009) A Prospective, Observational Registry of Patients with Severe Sepsis: The Canadian Sepsis Treatment and Response Registry. Critical Care Medicine, 37, 81-88. http://dx.doi.org/10.1097/CCM.0b013e31819285f0

[33] Blanco, J., Muriel-Bombín, A., Sagredo, V., Taboada, F., Gandía, F., Tamayo, L., et al. (2008) Incidence, Organ Dysfunction and Mortality in Severe Sepsis: A Spanish Multicentre Study. Critical Care, 12, R158. http://dx.doi.org/10.1186/cc7157

[34] Cheng, B.L., Xie, G.H., Yao, S.L., Wu, X.M., Guo, Q.L., Gu, M.N., et al. (2007) Epidemiology of Severe Sepsis in Critically Ill Surgical Patients in Ten University Hospitals in China. Critical Care Medicine, 35, 2538-2546. http://dx.doi.org/10.1097/01.CCM.0000284492.30800.00

[35] Schroder, J., Kahlke, V., Staubach, K.H., Zabel, P. and Stüber, F. (1998) Gender Differences in Human Sepsis. Archives of Surgery, 133, 1200-1205. http://dx.doi.org/10.1001/archsurg.133.11.1200

[36] Crabtree, T.D., Pelletier, S.J., Gleason, T.G., Pruett, T.L. and Sawyer, R.G. (1999) Gender-Dependent Differences in Outcome after the Treatment of Infection in Hospitalized Patients. JAMA, 282, 2143-2148. http://dx.doi.org/10.1001/jama.282.22.2143

[37] Wichmann, M.W., Inthorn, D., Andress, H.-J. and Schildberg, F.W. (2000) Incidence and Mortality of Severe Sepsis in Surgical Intensive Care Patients: The Influence of Patient Gender on Disease Process and Outcome. Intensive Care Medicine, 26, 167-172. http://dx.doi.org/10.1007/s001340050041

[38] Danai, P.A., Sinha, S., Moss, M., Haber, M.J. and Martin, G.S. (2007) Seasonal Variation in the Epidemiology of Sepsis. Critical Care Medicine, 35, 410-415. http://dx.doi.org/10.1097/01.CCM.0000253405.17038.43

[39] Brun-Buisson, C., Doyon, F., Carlet, J., Dellamonica, P., Gouin, F., Lepoutre, A., et al. (1995) Incidence, Risk Factors and Outcome of Severe Sepsis and Septic Shock in Adults. A Multicenter Prospective Study in Intensive Care Units. JAMA, 274, 968-974. http://dx.doi.org/10.1001/jama.1995.03530120060042

[40] Alberti, C. and Brun-Buisson, C. (2003) Epidemiology of Infection and Sepsis: A Review. Advances in Sepsis, 3, 4555.

[41] Ponce de León-Rosales, S.P., Molinar-Ramos, F., Dominguez-Cherit, G., Rangel-Frausto, M.S. and Vázquez-Ramos, V.G. (2000) Prevalence of Infections in Intensive Care Units in Mexico: A Multicenter Study. Critical Care Medicine, 28, 1316-1321. http://dx.doi.org/10.1097/00003246-200005000-00010 
[42] Rangel-Frausto, M.S., Pittet, D., Costigan, M., Hwang, T., Davis, C.S. and Wenzel, R.P. (1995) The Natural History of the Systemic Inflammatory Response Syndrome (SIRS). A Prospective Study. JAMA, 273, 117-123. http://dx.doi.org/10.1001/jama.1995.03520260039030

[43] Vincent, J.L., Bihari, D.J., Suter, P.M., Bruining, H.A., White, J., Nicolas-Chanoin, M.-H., et al. (1995) The Prevalence of Nosocomial Infection in Intensive Care Units in Europe. Results of the European Prevalence of Infection in Intensive Care (EPIC) Study. EPIC International Advisory Committee. JAMA, 274, 639-644. http://dx.doi.org/10.1001/jama.1995.03530080055041

[44] Alberti, C., Brun-Buisson, C., Burchardi, H., Martin, C., Goodman, S., Artigas, A., et al. (2002) Epidemiology of Sepsis and Infection in ICU Patients from an International Multicenter Cohort Study. Intensive Care Medicine, 28, 108121. http://dx.doi.org/10.1007/s00134-001-1143-Z

[45] Hollo, V., Amato-Gauci, A., Kodmon, C. and Manissero, D. (2009) Tuberculosis in the EU and EEA/EFTA Countries: What Is The Latest Data Telling Us? Eurosurveillance, 14, pii 19151.

\section{List of Abbreviations}

AIDS-Acquired ImmunoDeficiency Syndrom; CASS - Community-acquired severe sepsis; CI-Confidence Interval; ESBL_extended spectrum beta-lactamase; MDR_-Multidrug resistant; HIV-Human Immunodeficiency Virus; ICU_-Intensive Care Unit; IQR — inter-quartile range; LOS — length of stay; MRSA —Methicillin resistant staphylococcus aureus; MSSA-Methicillin sensitive staphylococcus aureus; OR_Odds Ratio; SAPS II—Simplified Acute Physiological Score; SD—standard deviation; SIRS—Systemic inflammatory response syndrome; SS-Severe sepsis. 